\title{
A percepção docente sobre educação ambiental e sustentabilidade nas escolas municipais de Capitão Poço, Pará, Brasil
}

\section{Raimundo Augusto Borges Neto* e Dioniso de Souza Sampaio}

Universidade Federal do Pará. Instituto de Estudos Costeiros (IECOS). Faculdade de Ciências Naturais (FACIN). Bragança-PA, Brasil (CEP 68600-000). *E-mail: prof.augustocn@gmail.com.

Resumo. Este artigo consiste em uma avaliação sobre o tema sustentabilidade e meio ambiente, juntamente com os professores da Rede Municipal de Educação de Capitão Poço, Estado do Pará, especificamente nas escolas "Francisco Marques", "Walmeire Borges" e "Mariana das Graças". Esta pesquisa tem a finalidade e o intuito de compreender a sensibilização e hábitos de consumo dos professores das referidas escolas. Juntamente com a Secretaria Municipal de Educação foi feito um levantamento da quantidade de escolas e professores atuando na educação básica e ensino fundamental maior ( $6^{\circ}$ ao $9^{\circ}$ ano), foi traçado um perfil dos professores com idade, tempo de formação e tempo de atuação docente, além dos hábitos e níveis de esclarecimento em relação à educação ambiental, com um questionário semiestruturado composto por 20 perguntas. Não contando somente com professores de ciências, mas sim, com professores de todas as disciplinas da grade curricular, procurando fazer uma interdisciplinaridade. Foi abordado também a questão da conscientização dos mestres, em relação a práticas sustentáveis. Como resultado final, os professores demonstraram conhecimento razoável a respeito do Meio Ambiente. Mas é claro que uma ação de intervenção é necessária, visto que, ainda há muita desinformação no meio educacional no que se refere à educação ambiental.

Palavras-chave: Educação ambiental; Ensino público; Sustentabilidade; Estado do Pará.

Abstract. The teaching perception of environmental education and sustainability in municipal schools in the Municipality of Capitão Poço, Pará, Brazil. The following work consists of an assessment on the theme of sustainability and the environment, together with teachers from public education network of Municipality of Capitão Poço, Pará State, North of Brazil, specifically in the schools "Francisco Marques", "Walmeire Borges" and "Mariana das Graças". This research has the purpose and the intention to understand the awareness and consumption

Recebido

29/03/2020

Aceito

21/06/2020

Disponível on line

22/06/2020

Publicado

31/08/2020

Acesso aberto

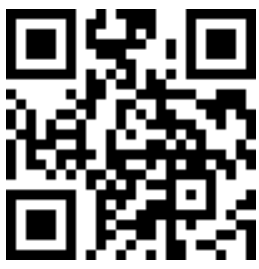

ORCID

(1) 0000-0002-2216-3201

Raimundo Augusto Borges Neto

D 0000-0002-2688-6001

Dioniso de Souza

Sampaio

ISSN 2359-1412/RBGAS-2020-0056/2020/7/16/6/537

Rev. Bras. Gest. Amb. Sustent.

http://revista.ecogestaobrasil.net 
habits of the teachers in those schools. Together with the Municipal Education Departament, a survey was made of the schools number and teachers working in basic, major and elementary education (6th to 9th grade), a profile of teachers with age, time of training and time of experience was drawn up, in addition to habits and levels of clarification in relation to environmental education, with a semi-structured questionnaire consisting of 20 questions. Not only with science teachers, but with teachers from all disciplines in the curriculum, seeking to make an interdisciplinary work. The issue of raising teachers' awareness of sustainable practices was also addressed. As a final result, the teachers demonstrated reasonable knowledge about the environment. But it is clear that an intervention action is necessary, since there is still a lot of misinformation in the educational environment with regard to Environmental Education.

Keywords: Environmental education; Public education; Sustainability; Pará State; Brazil.

\section{Introdução}

O tema sustentabilidade vem sendo debatido e estudado durante anos. E tudo começa na educação ambiental, visto que é uma problemática importante, temos que encontrar meios e formas de conscientizar mais pessoas, começando pelos mais jovens nas nossas escolas. Meio ambiente é um assunto bem abrangente e importante para a formação de um ser humano, é saber como tratar de forma sustentável e eficiente o meio que nos cerca, daí a necessidade de um entendimento de como está sendo repassado esse assunto nas escolas municipais de Capitão Poço. 0 município tem uma forte influência da agricultura, sendo importante analisar bem e com cautela a educação ambiental desenvolvida no município., tendo em vista este contexto agrícola da cidade, uma prática muito corriqueira e eficiente, em certos casos, é a montagem de hortas nas escolas. Como cita Morgado (2006, p. 9-10):

\footnotetext{
Diante dessa problemática a horta escolar torna-se um elemento capaz de desenvolver temas envolvendo educação ambiental e alimentar, pois além de conectar conceitos teóricos e práticos auxiliando o processo de ensino e aprendizagem, se constitui como uma estratégia capaz de auxiliar no desenvolvimento dos conteúdos de forma interdisciplinar, distribuídos em assuntos trabalhados por temas transversais.
}

Segundo Cuba (2010, p. 28) “a educação ambiental é conteúdo e aprendizado, é motivo e motivação, é parâmetro e norma. Vai além dos conteúdos pedagógicos, interage com o ser humano de forma que a troca seja uma retroalimentação positiva para ambos". Essa interação é vantajosa para ambas as partes, por tanto, a educação ambiental tem muita importância no âmbito escolar, não só para formação de bons profissionais, mas também na formação de bons cidadãos. Um diálogo sobre a política dos $3 \mathrm{R}$ 's, faz-se importante devido a necessidade de manutenção dos recursos naturais, a capacidade de reciclar, reduzir e reutilizar. Todos estes temas estão englobados na temática da E.A, dentro desta política dos $3 \mathrm{R}$ 's, encontramos uma prática eficaz e benéfica ao meio 
ambiente, a compostagem. Com sua finalidade sendo de reutilizar dejetos e variados resíduos, para obtenção de adubo fertilizante.

A sustentabilidade em si precisa ser ensinada de geração a geração, trabalho esse que pertence a todos, mas em especial aos professores, não por moda ou estética. Como citam as autoras Courela e César (2006, p. 81) "mas porque consideramos uma obrigação ética do professor tentar proporcionar ambientes de aprendizagem favoráveis aos seus alunos, não teria qualquer substância, reduzindo-se a uma mera operação de cosmética, se não passasse pela avaliação". O professor, em teoria, possui toda a condição de propiciar um cenário favorável para o ensino deste tema tão importante. A Educação Ambiental, por sua vez, surge como um assunto rico em conteúdo tendo que ser tratado como tal, mas não se limitando a uma só disciplina curricular, deixando o tema livre para se fazer uma interdisciplinaridade, como dizem Medeiros et. al. (2011):

\begin{abstract}
Como perspectiva educativa, a educação ambiental deve estar presente, permeando todas as relações e atividades escolares, desenvolvendo-se de maneira interdisciplinar, para refletir questões atuais e pensar qual mundo queremos, e, então, pôr em prática um pensamento ecologista mundial. A Educação Ambiental não deve se destinar como uma nova disciplina do currículo escolar, precisa ser uma aliada do currículo, na busca de um conhecimento integrado que supere a fragmentação tendo em vista o conhecimento.
\end{abstract}

Effting (2007, p. 6) menciona que a "educação ambiental é um elemento essencial para uma educação global, orientada para a resolução dos problemas, em favor do bemestar da comunidade humana". É bem interessante analisar essa afirmação, visto à necessidade de evolução constante da humanidade, o que se torna um tanto quanto difícil sem essa conscientização provocada pela Educação Ambiental.

Este trabalho é guiado pelas contribuições teóricas de Sulaiman (2011), que diz que a educação escolar não é a única fonte de aprendizado do ser humano, Martins (2018), que fez uma pesquisa nos mesmos moldes deste trabalho na cidade litorânea de Salinópolis, Pará. Reigota (2007), que estuda a pesquisa ambiental no Brasil fazendo uma ponte com outros países e verificando de que forma o estudo ambiental começou nestes determinados países, Silva e Campina (2011) que analisam a educação ambiental na mídia e nas práticas escolares, buscando entender se havia um consenso entre as partes em usar o espaço escolar muito além da sala de aula.

Ainda de acordo com Effting (2007, p. 22) "é no sentido de promover a articulação das ações educativas voltadas às atividades de proteção, recuperação e melhoria socioambiental, e de potencializar a função da educação para as mudanças culturais e sociais, que se insere a educação ambiental no planejamento estratégico para o desenvolvimento sustentável". A contextualização juntamente com a interdisciplinaridade se fazem necessárias no âmbito escolar, já que a Educação Ambiental não possui uma disciplina especifica como cita Kato et al. (2011, p.2):

A inserção da Educação Ambiental (EA) no currículo escolar formal tem sido objeto de discussão e polêmicas há algum tempo, não há um consenso sobre a forma mais adequada de inseri-la na escola: a criação de uma disciplina específica sobre o tema ou se a EA deve permear o currículo como um todo, aos adeptos da segunda ideia ainda fica a questão de como realizar esse processo. 0 sistema de ensino organizado a partir de disciplinas escolares, a carga horária de estudos, a quantidade de conteúdo específicos das áreas a serem ministradas, bem como a formação especializada dos professores mostram-se muitas vezes incompatíveis com a demanda de uma Educação Ambiental que vislumbra uma perspectiva interdisciplinar, que busca a complexidade do ambiente e está vinculada aos aspectos sociais, culturais e econômicos da realidade de vivências do aprendiz.

Rev. Bras. Gest. Amb. Sustent., 2020, vol. 7, n. 16, p. 537-552. 
O objetivo geral desse trabalho é analisar como os temas sustentabilidade e meio ambiente estão sendo abordados pelos professores, como eles trabalham essa temática, se ficam "presos" à sala de aula ou se trabalham isso fora das quatro paredes. Em relação a objetivos específicos, outro ponto abordado é se a escola a qual ministram suas aulas possuem áreas/espaços verdes e se fazem uso para fins educativos ou para descanso ou se simplesmente utilizam essas áreas nas escolas. Tentamos entender também como a rotina e realidade da cidade em termos de órgãos públicos responsáveis e se os próprios professores fazem sua parte em tentar viver de forma sustentável.

\section{Metodologia}

Segundo o último senso do IBGE, o município possui 51.893 habitantes, a estimativa no ano de 2019 é de aproximadamente 54.303. 0 município apresenta 3,3\% das casas com esgotamento sanitário adequado, 32,5\% de domicílios urbanos em vias públicas com arborização e 4,2\% de domicílios urbanos em vias públicas com urbanização adequada (presença de bueiro, calçada, pavimentação e meio-fio) (IBGE, 2019).

Este trabalho leva em conta o caráter quali-quantitativo, com a aplicação de um questionário semiestruturado. No que diz respeito à educação há 101 escolas municipais distribuídas no território, sendo 14 na zona urbana e 77 na zona rural. Em relação à abordagem utilizada neste trabalho, foi escolhida a pesquisa qualitativa e quantitativa que faz uso da quantidade de dados obtidos, ou seja, completamente o inverso da pesquisa qualitativa, que busca a qualidade/essência dos dados. Essa modalidade de pesquisa foi escolhida dentre muitas outras modalidades, como diz Silva (1998, p.3):

Durante muito tempo prevaleceu mesmo nas chamadas ciências "softs", como as humanas e sociais, a predominância desse tipo de postulação positivista nas pesquisas. Ou seja, para ser considerado científico o estudo precisava demonstrar preenchimento de critérios previstos nessa visão unitária de ciência. Nela só é considerado científico o conhecimento gerado dentro de um processo que cumpre os requisitos sistemáticos de relevância explicativa e de contrastabilidade empírica, sejam estas de caráter dedutivista ou geradas através de explicações probabilísticas. Essa visão unitária de ciência fez e faz ainda com que muitos falem em "método científico" no singular, como se houvesse sempre uma única forma adequada de pesquisa.

No que diz respeito à abordagem utilizada, este trabalho consiste em uma pesquisa exploratória tentando abranger o maior número de professores entrevistados na escola. Para Gil (2002, p. 1):

Estas pesquisas têm como objetivo proporcionar maior familiaridade com o problema, com vistas a tomá-lo mais explícito ou a constituir hipóteses. Pode-se dizer que estas pesquisas têm como objetivo principal o aprimoramento de ideias ou a descoberta de intuições. Seu planejamento é portanto, bastante flexível, de modo que possibilite a consideração dos mais variados aspectos relativos ao fato estudado. Embora o planejamento da pesquisa exploratória seja bastante flexível, na maioria dos casos assume a forma de pesquisa bibliográfica ou de estudo de caso.

Em setembro de 2019 foi solicitada para a Secretária Municipal da Educação (SEMED) a quantidade de escolas da zona urbana e rural do município, que atendessem o ensino fundamental maior e também o número de professores que trabalham nessas escolas do 6으 ao 9o ano. As atividades de campo com aplicação do questionário aconteceu em outubro de 2019. 
No total são cinco escolas que atendem ao ensino fundamental maior, alvo principal desta pesquisa. Foram escolhidas três escolas baseado o levantamento feito com a SEMED e nas três escolas selecionadas trabalhavam um total de 38 professores, mas durante a pesquisa só foi visto 27 professores (por motivos de licenças ou motivos não esclarecidos), onde desses 27 apenas 20 aceitaram participar e responder o questionário. Na escola "Walmeire Borges" 6 de 9 professores responderam, na escola "Mariana das Graças", 7 dos 16 responderam e na escola "Francisco Marques" apenas 7 de 13 responderam (levando em consideração o número que a SEMED repassou). 0 quantitativo de professores presentes na pesquisa se deu pela presença dos mesmos, durante os dias de aplicação dos questionários e coleta de dados e também pela disponibilidade e vontade dos professores. 0 que foi dito para justificar a falta de professores nas escolas foi que, alguns estavam de licença, outros não trabalhavam mais e alguns simplesmente não aparecem desde o começo do ano. Concluindo, apenas 20 professores aceitaram participar da pesquisa.

Seguindo, a pesquisa foi realizada em forma de aplicação de um questionário elaborado e semiestruturado com perguntas objetivas e subjetivas. 0 questionário foi aplicado no mês de outubro de 2019, juntamente com o Termo de Consentimento Livre Esclarecido (TCLE). Um ponto abordado pelo questionário foi a vida que os professores levam, não só saber se aplicavam suas aulas de modo sustentável, mas também se seus costumes, hábitos e manias andavam lado a lado com seus ensinamentos na escola. 0 questionário é composto por 20 perguntas, avaliando também o perfil dos entrevistados, como por exemplo: sexo, idade, disciplina de atuação, formação, tempo de formação e tempo de atuação. 0 questionário conta com 17 perguntas de múltipla escolha e 3 perguntas subjetivas, aberta a discussões.

As perguntas do questionário são as seguintes: 1) Você se considera informado a respeito de temas como meio ambiente e ecologia?; 2) Com que frequência você trabalha e/ou relaciona ou correlaciona assuntos de meio ambiente em sala de aula?, 3) Qual o principal problema ambiental na escola que você trabalha?; 4) Você costuma reciclar no seu dia a dia?; 5) Qual destas alternativas permite conseguir melhor solução de um problema ambiental que o atinge?; 6) Conhece algum grupo, entidades ou organização que trabalhe pela proteção do meio ambiente no seu município?; 7) Você considera o órgão de defesa do meio ambiente do município atuante?; 8) Como se considera quanto aos assuntos relacionados com o meio ambiente?; 9) Quais ações para proteger o meio ambiente, você toma no dia a dia?; 10) A solução dos problemas ambientais na sua escola, em sua opinião, depende mais?; 11) Como você avalia a situação das escolas municipais de Capitão Poço nas questões ambientais?; 12) Na escola você habitualmente: (A) sim (B) não (C) as vezes (D) não sei; 13) Em relação aos resíduos, quais ações sustentáveis você considera mais importantes para a escola implementar? (Escolha duas opções); 14) Você utiliza as áreas verdes e praças presentes na escola para convivência e/ou descanso?; 15) Uma das práticas mais eficientes em relação a sustentabilidade, é a compostagem. Você conhece ou faz uso dessa prática?; 16) Com qual frequência você trabalha o tema compostagem nas suas aulas relacionando ou correlacionando com sua disciplina de atuação?; 17) Na escola que você atua, existe um espaço útil para uma prática de compostagem?; 18) Qual a diferença entre os três R's da sustentabilidade (reduzir, reciclar e reutilizar)?; 19) 0 que você entende por sustentabilidade?; 20) Sua escola realiza ações sustentáveis? Cite quais.

A análise dos dados foi feita calculando a quantidade de respostas por cada alternativa que a pergunta possui, tirando assim uma porcentagem por alternativa, perguntas com a marcação de apenas uma resposta é calculada para obtenção de $100 \%$. Há uma questão sem limite de opções, neste caso, foi calculada a porcentagem de cada alternativa marcada e na questão em si, como nos outros casos. 


\section{Caracterização das Escolas}

Escola Municipal de Ensino Fundamental Walmeire Borges: Fundada em dezembro de 2001, a escola Walmeire Borges atende um total de 382 alunos (SEMED, 2019), divididos nos turnos da manhã e tarde. Possui internet, água potável, sistema de saneamento adequado, como nove salas de ensino e 52 funcionários trabalhando diariamente. Possui das séries iniciais até as séries finais do ensino fundamental. Nove docentes lecionam as disciplinas básicas, português, matemática, ciências, geografia, história, educação física, estudos amazônicos, ensino religioso, inglês e artes.

Escola Municipal de Ensino Fundamental Mariana das Graças da Silva Aguiar: A escola municipal "Mariana das Graças da Silva Aguiar" foi fundada no dia 14 de abril de 2015, atende um total de aproximadamente de 740 alunos (SEMED 2019), distribuídos nos turnos da manhã, tarde e noite. Com acréscimo do ensino de jovens e adultos (EJA) funcionando no turno da noite. A escola possui saneamento básico adequado, fornece merenda escolar para os alunos, mas não possui internet e há apenas dois computadores para uso administrativo. Em relação aos docentes do ensino fundamental maior, 16 trabalham no turno da tarde, atendendo os componentes curriculares básicos como português, matemática, ciências, geografia, história, educação física, estudos amazônicos, ensino religioso, inglês e artes.

Escola Municipal de Ensino Fundamental Francisco Marques Aguiar: A escola Francisco Marques, foi fundada no dia 30 de março de 1978. Possui 31 funcionários, possui internet, com dois computadores para uso administrativo, água potável, saneamento básico adequado, com cinco salas de aulas, sala dos professores, sala da direção, cozinha e banheiros. Atende um total de 306 alunos, divididos nos turnos da manhã, tarde e noite com acréscimo da EJA (turno da noite). Conta com 13 docentes (SEMED, 2019), na área do ensino fundamental maior, que lecionam as disciplinas de português, matemática, ciências, geografia, história, educação física, estudos amazônicos, ensino religioso, inglês e artes.

\section{Resultados e discussão}

Como foi dito acima, foi analisado o perfil dos professores entrevistados, com isso, notou se que $60 \%$ são do sexo feminino e $40 \%$ do sexo masculino, quanto ao tempo de formação docente temos o menor tempo em um ano e o maior tempo 27 anos, já o tempo de atuação temos professores com muita experiência de sala de aula, um com 31 anos trabalhados e novatos também, com um ano de atuação. No que diz respeito o nível de formação, praticamente $100 \%$ com nível superior, 95\% com nível superior e 5\% com um curso na igreja (corresponde a uma participante, professora de Ensino Religioso). Dentro desses $95 \%$ há um professor de história com mestrado na área (que corresponde a 5\% dos professores entrevistados).

Segundo o Anuário brasileiro de Educação Básica de 2019 (Cruz e Monteiro, 2019), sobre o nível de escolaridade dos professores da educação básica, 79,9\% dos professores possuem nível superior, $10,7 \%$ possuem só o ensino médio, já 9,2\% possuem o magistério e $0,3 \%$ só possuem o ensino fundamental. Chegamos aos componentes curriculares, tendo em vista que é importante ressaltar que não foi abordado somente professores de ciências, mas sim de todas as disciplinas curriculares (Figura 1).

Progredindo agora para a avaliação do questionário, a questão número 1 diz assim "você se considera informado a respeito de temas como meio ambiente e ecologia?" de acordo com os dados obtidos $55 \%$ se consideram muito informados, $40 \%$ pouco informados e apenas 5\% (corresponde a uma resposta) nem um pouco informado. Esta questão torna-se de suma importância para começarmos a analisar o saber de nossos educadores a respeito de meio ambiente e ecologia, consequentemente sustentabilidade. 
Como disse Jacobi (2003) o professor é o elo mais forte e importante, fazendo uma ligação entre aluno e o meio que o cerca.

\section{Componentes Curriculares}

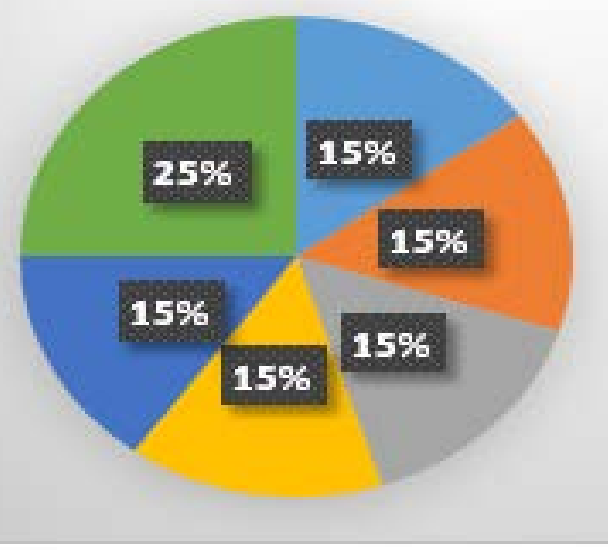

nortuguês

- Matematica

Eiências

História

Geografia

Demais Diciplinas

Figura 1. Componentes curriculares.

Como foi dito, não somente professores de ciências foram analisados. Então vale ressaltar e verificar se o tema meio ambiente se encaixa nas outras disciplinas pesquisadas e também a frequência que esse tema entra em debate na sala de aula, logo a questão número 2 "com que frequência você trabalha e/ou relaciona ou correlaciona assuntos de meio ambiente em sala de aula?", onde $40 \%$ fala que somente em assuntos específicos, $25 \%$ dizem que sempre relacionam e $35 \%$ às vezes relacionam esse assunto em sala de aula (Figura 2).

\section{Com que frequência você trabalha e/ou relaciona ou correlaciona assuntos de meio ambiente em sala de aula?}

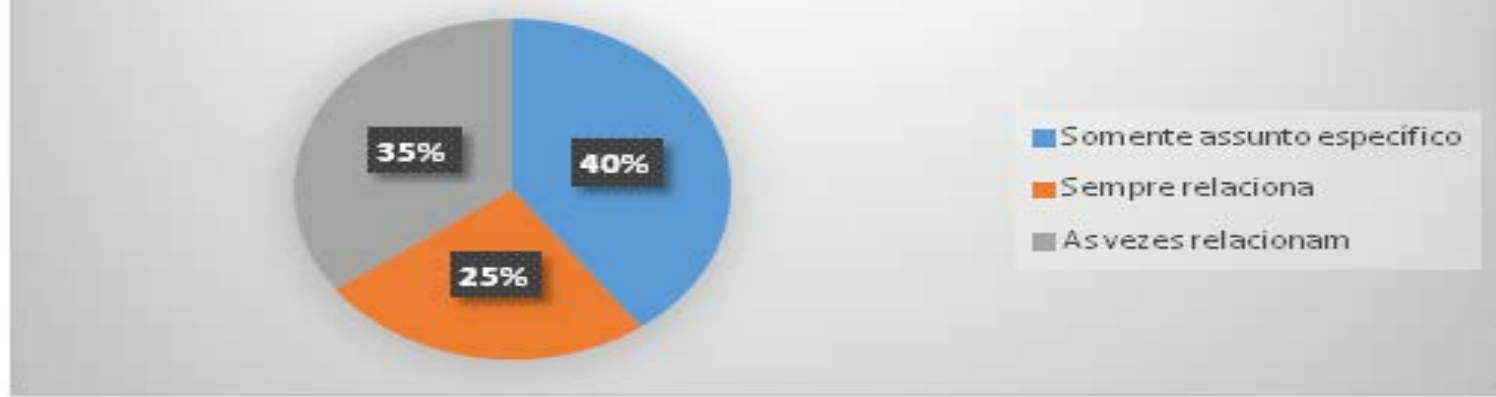

Figura 2. Assuntos de meio ambiente e sala de aula.

Tendo em vista esse dado, podemos pensar que uma solução seria os temas transversais, com suas temáticas interessantes e hábeis de se trabalhar em várias áreas. 
Como relata os Parâmetros Curriculares Nacionais (PCN), do Ministério da Educação, as temáticas sociais possuem uma grande importância:

Se a escola pretende estar em consonância com as demandas atuais da sociedade, é necessário que trate de questões que interferem na vida dos alunos e com as quais se veem confrontados no seu dia-a-dia. As temáticas sociais, por essa importância inegável que têm na formação dos alunos, já há muito têm sido discutidas e frequentemente incorporadas aos currículos das áreas ligadas às Ciências Naturais e Sociais, chegando até mesmo, em algumas propostas, a constituir novas áreas (MEC, 1997, p. 44-45).

Na questão número 4, "você costuma reciclar no seu dia a dia?" 30\% responderam que não, $10 \%$ responderam que sim e $60 \%$ responderam que as vezes reciclam. Sabemos da importância de reciclar, pelo impacto causado ao meio ambiente e pela durabilidade dos produtos. Como diz Layrargues (2002, p. 3):

A vida útil dos produtos torna-se cada vez mais curta, e nem poderia ser diferente, pois há uma união entre a obsolescência planejada e a criação de demandas artificiais no capitalismo. É a obsolescência planejada simbólica, que induz a ilusão de que a vida útil do produto esgotou-se, mesmo que ele ainda esteja em perfeitas condições de uso.

Ressaltando a cultura do consumismo, onde prega que as coisas foram feitas para durar pouco tempo, sem alternativas para prolongar a vida útil desses materiais, sendo assim, reciclagem acaba ficando em segundo plano.

Na questão número 5, que é "qual destas alternativas permite conseguir melhor solução de um problema ambiental que o atinge?" 50\% responderam que procurar um órgão público é a solução, 25\% responderam que é necessário mobilizar a população, 20\% acham que sensibilizar os alunos é o melhor a se fazer e apenas 5\% responderam que procurar organizações de defesa do meio ambiente (Figura 3).

\section{Qual destas alternativas permite conseguir melhor solução de um problema ambiental que o atinge?}

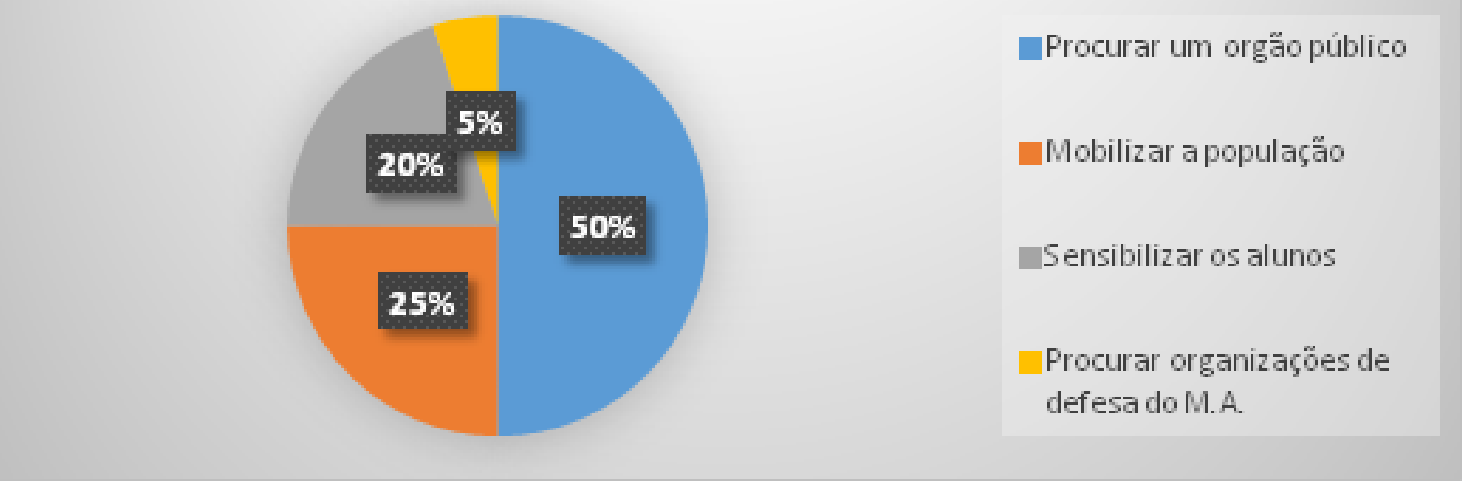

Figura 3. Soluções e problemas ambientais.

Opção com um quarto (25\%) das respostas foi mobilizar a população do bairro em que a escola está inserida, se cada um fizer sua parte, a situação melhora. Esses dados se 
fazem interessantes para a próxima pergunta do questionário, em relação aos órgãos públicos da cidade. Procurar um órgão público foi escolhido por $50 \%$ dos entrevistados.

Seguindo com as perguntas, chegamos a questão de número 6 "Conhece algum grupo, entidades ou organização que trabalhe pela proteção do meio ambiente no seu município?", 65\% responderam que não conhecem nenhum órgão ou ONG que faz esse trabalho, já 35\% relataram que conhecem e foram unânimes em citar a SEMMA (Secretária Municipal de Meio Ambiente).

Para Castoldi et al. (2009, p. 63), o "ponto relevante do trabalho com a educação ambiental é o desafio que os professores enfrentam para trabalhar temas ambientais, as dificuldades começam em diferenciar ecologia e educação ambiental cujos conteúdos se intercalam, tornando difícil separa-los..."

Seguindo o questionário, questão número 8 "Como se considera quanto aos assuntos relacionados com o meio ambiente?", Tivemos um empate nas respostas com $50 \%$ dizendo que são muito interessados e $50 \%$ dizendo que não se interessam tanto assim pelo assunto. Foi possível perceber que pouquíssimos professores de disciplinas da Área de "Humanas" (Língua Portuguesa, História, Geografia) se interessavam de verdade pelo assunto, dentre essa categoria professores de geografia se mostraram mais preocupados com o assunto. A grande maioria dos 50\% interessados foram profissionais da área de "exatas e biológicas" (matemática, ciências, estudos amazônicos)

Voltando o foco para dentro das escolas. Temos a questão 10 que diz "A solução dos problemas ambientais na sua escola, em sua opinião, depende mais?". 90\% responderam que depende exclusivamente das pequenas ações de todos no dia a dia, já $10 \%$ não souberam responder (Figura 4).

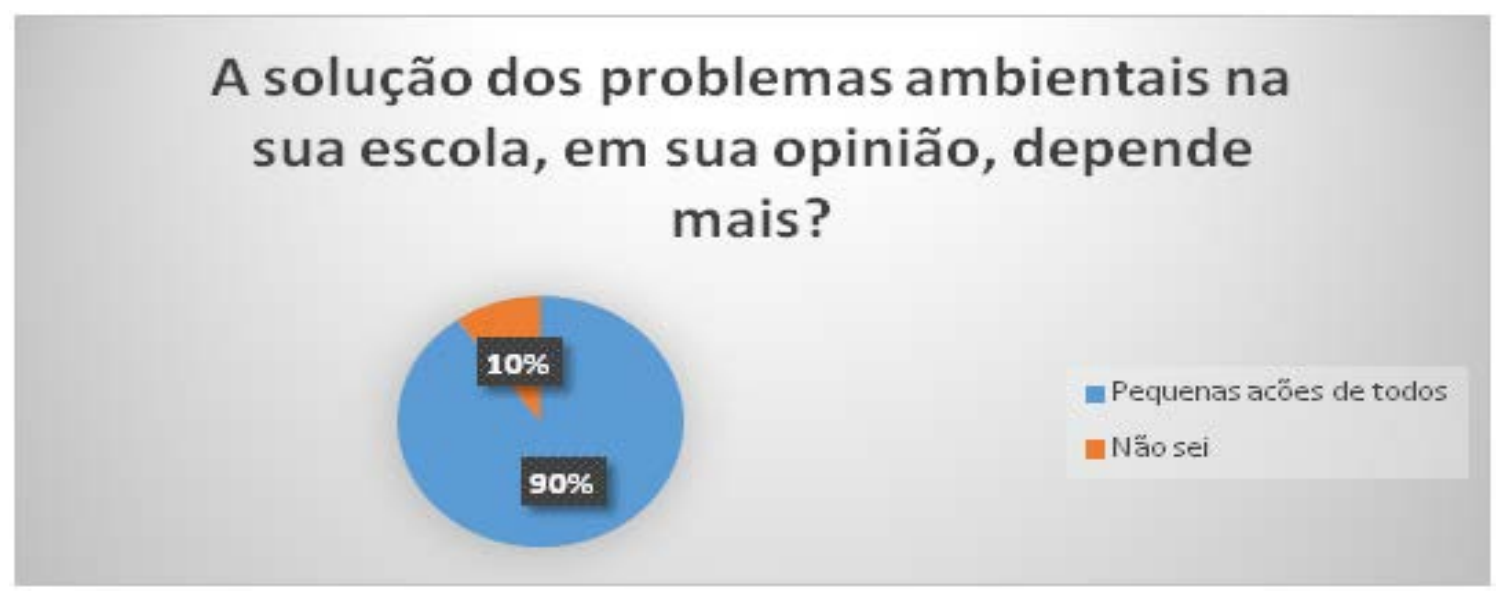

Figura 4. Problemas ambientais e as escolas.

Se pararmos para analisar, se cada um fizer sua parte, podemos mudar o cenário atual do meio ambiente, isso não ajudará somente a nossa geração, mas sim, as próximas gerações, nossos filhos, nossos netos e afins. Nesta questão também havia a alternativa que dizia assim "Das decisões governamentais e das grandes empresas" mas não nenhuma marcação. Narcizo (2009, p. 88) tem uma visão ampla e simplificada sobre a importância do meio ambiente, como ele mesma cita:

A educação ambiental deve ser trabalhada na escola não por ser uma exigência do Ministério da Educação, mas porque acreditamos ser a única forma de aprendermos e 
ensinarmos que nós, seres humanos, não somos os únicos habitantes deste planeta, que não temos o direito de destruí-lo, pois da mesma forma que herdamos a terra de nossos pais, deveremos deixa-la para nossos filhos.

Na próxima pergunta chegamos a tratar de hábitos que acontecem na escola, hábitos esses que servem como modelos e ensinamentos para quem está vendo. Trata-se da questão número 12 "Na escola você habitualmente:" onde os entrevistados tinham as opções A - sim, B - não, C - às vezes, D - não sei. (Tabela 1).

Tabela 1. Na escola você habitualmente.

\begin{tabular}{|l|c|c|c|c|}
\hline Itens & $\begin{array}{c}\text { Sim } \\
(\%)\end{array}$ & $\begin{array}{c}\text { Não } \\
\text { (\%) }\end{array}$ & $\begin{array}{c}\text { Às vezes } \\
\text { (\%) }\end{array}$ & $\begin{array}{c}\text { Não sei } \\
\text { (\%) }\end{array}$ \\
\hline $\begin{array}{l}\text { Desliga as luzes e ventiladores ou centrais de ar ao sair } \\
\text { da sala de aula. }\end{array}$ & 90 & 5 & 5 & - \\
\hline $\begin{array}{l}\text { Desliga as torneiras de água quando as encontra } \\
\text { ligadas. }\end{array}$ & 90 & - & 10 & - \\
\hline $\begin{array}{l}\text { Sensibiliza os alunos quanto ao descarte adequado do } \\
\text { lixo dentro e fora da sala. }\end{array}$ & 85 & - & 15 & - \\
\hline Sensibiliza quanto ao desperdício de alimentos. & 70 & 10 & 20 & - \\
\hline Aproveita ao máximo os materiais didáticos. & 100 & - & - & - \\
\hline $\begin{array}{l}\text { Imprime ou faz cópia da maioria dos documentos em } \\
\text { frente e verso. }\end{array}$ & 100 & - & - & - \\
\hline Recicla ou reutiliza os materiais didáticos utilizados. & 80 & - & 20 & - \\
\hline $\begin{array}{l}\text { Conscientiza quanto ao reaproveitamento de restos } \\
\text { vegetais da merenda escolar. }\end{array}$ & 50 & 5 & 45 & - \\
\hline Utiliza papel reciclável. & 30 & 20 & 40 & 10 \\
\hline Conscientiza quanto o desperdício de agua. & 80 & 10 & 10 & - \\
\hline
\end{tabular}

Durante a pesquisa muitos professores ficaram confusos nesta questão, pois não se lembravam de fato se faziam ou não as alternativas propostas. Alternativas com um maior peso ambiental tiveram boa aprovação como as conscientizações de desperdício de água e restos alimentares.

Na pergunta 13, referente a temática de resíduos "Em relação aos resíduos, quais ações sustentáveis você considera mais importantes para a escola implementar?”, onde 60\% selecionou "Coleta seletiva dos resíduos recicláveis" e 35\% escolheu a "Compostagem do lixo orgânico", 20\% "Parceria com catadores de materiais recicláveis "e 85\% "Práticas/oficinas de reaproveitamento de resíduos diversos". Com base nestes dados, constamos uma concordância e ligação entre a coleta e práticas de reaproveitamento dos resíduos, podendo até se tornar um ciclo sustentável.

Nas próximas perguntas com alternativas do questionário, foi dado enfoque em uma das principais práticas relacionadas a sustentabilidade, trata-se da compostagem, já que dois dos pontos mais fortes da cidade são a agricultura e o comércio, e a prática da compostagem consiste na confecção de um material para uso próprio como também fonte de renda auxiliar para as famílias da zona rural, essa prática não é a principal ligação com a questão da agricultura sustentável, mas devido esse cenário municipal se faz importante um entendimento a respeito deste manejo de resíduos. A compostagem, mais aprofundada, consiste no uso de materiais que seriam descartados para o lixo, para se fazer um fertilizante para plantas e plantações, tão eficaz quanto muitos agrotóxicos, só que sendo 100\% sustentável. Para adentrar o tema tivemos que saber se os professores 
faziam ideia do que é compostagem, já que as escolas como um todo, produz uma quantidade demasiada de resíduos orgânicos, como cita os autores Brambilla \& Matsushita (2014, p. 184): “As escolas geram grandes volumes de resíduos orgânicos que podem ser transformados em compostos para serem utilizados nas hortas e nos jardins da própria escola, realizando uma prática ambiental e ampliando o conhecimento dos alunos...". Sendo assim temos a questão número 15 "Uma das práticas mais eficiente em relação a sustentabilidade, é a compostagem. Você conhece ou faz uso dessa prática?". Tivemos uma boa porcentagem em relação as pessoas que conheciam (Figura 5).

\section{Uso da compostagem}

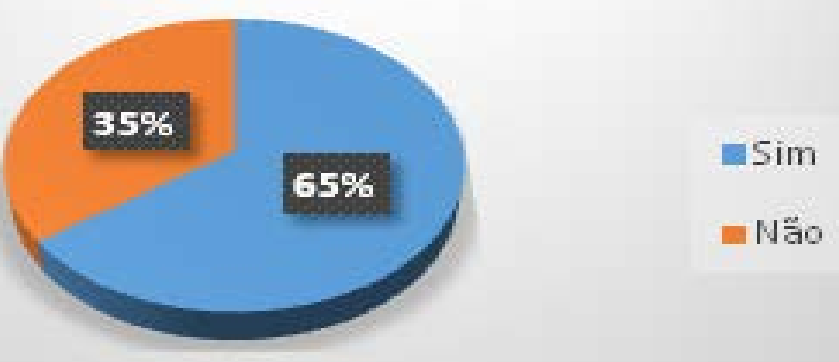

Figura 5. Compostagem e a escola.

Na questão 16, foi perguntado o seguinte "Com qual frequência você trabalha o tema compostagem nas suas aulas relacionando ou correlacionando com sua disciplina de atuação?". Como já era esperado, pode se notar que o tema é mais relacionado em disciplinas mais especificas como ciências e estudos amazônicos (Figura 6).

\section{Relacionam o tema compostagem...}

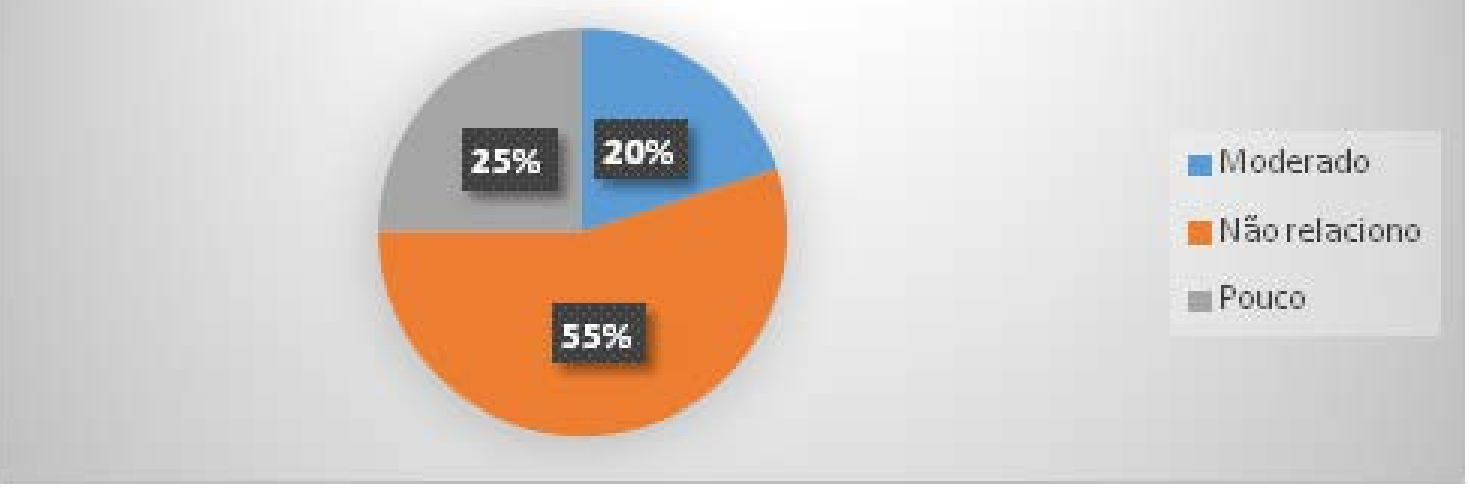

Figura 6. Relações com o tema compostagem na escola. 
Em disciplinas como Língua Portuguesa e Matemática os professores disseram que não relacionam o tema compostagem em suas aulas e poucos marcaram dizendo que relacionam "pouco" ou "moderado" já que é um tema complicado é bastante especifico da área da ciência. Lembrando que nenhum professor escolheu a opção "Muito".

Para concluir o questionário, foram estabelecidas três perguntas abertas a discursão com a finalidade e propósito de obter respostas mais pessoais dos professores. A primeira, questão número 18, foi "Qual a diferença entre os três R's da sustentabilidade (reduzir, reciclar e reutilizar)", o Ministério do Meio Ambiente (MMA) fala que o princípio básico dos três R's de sustentabilidade (reduzir, reciclar e reutilizar) é a base para resolver e solucionar os problemas do lixo. Levando em consideração tudo isso, essa é a melhor solução para evitar o acumulo demasiado de resíduos adotando os padrões de consumo sustentável, sendo assim, poupando os recursos naturais eliminando os desperdícios (MMA, 2013).

Nas perguntas subjetivas da pesquisa, foi questionado sobre a diferença dos três R's da sustentabilidade. Foi possível ver que grande parte dos professores não tem domínio sobre o tema, cerca de $40 \%$ sequer respondeu ao questionamento, e foi bem interessante ver alguns que responderam, com uma certa dúvida pedindo até um certo suporte da parte do entrevistador, para se recordarem do que se tratava, até mesmo a professora de ciências não se recordava do que se tratava o assunto. Aos que responderam mostraram domínio do tema, tendo todas as respostas com o padrão de reduzir o lixo produzido, mas com palavras diferentes para cada questionário:

Reduzir os gastos, reutilizar para poupar, reciclar para diminuir o desgaste do meio ambiente. Professor do Colégio "Francisco Marques" da área de Ciências.

Reduzir o gasto dos recursos naturais; Reciclar para diminuir o descarte no meio ambiente; Reutilizar o que ainda tem serventia". Professor de Geografia da Escola "Walmeire Borges".

Reciclar é a maneira pela qual podemos transformar determinados resíduos sólidos em novos produtos ou materiais a partir da transformação de suas propriedades químicas, físicas, físico-químicas e/ou biológicas. Em se tratando de reutilizar nada mais é que reaproveitar os resíduos sólidos sem que passem por suas transformações químicas, físicas, físico-químicas e/ou biológicas, possibilitando novas utilidades ao que antes poderia ser apenas um resíduo sólido à ser descartado. E reduzir se trata de limitar o consumo de quaisquer produtos, dando preferência àqueles que sejam de menor potencial produtivo de resíduos e que sejam de maior durabilidade (MMA, 2013).

1 - Reduzir, diminuir consumo de bens e serviços, utilizar apenas o necessário. 2 Reutilizar, prolongar a utilidade dos produtos que iriam para o lixo. 3 - Reciclar, dar outro destino ao lixo. Professora da Escola "Francisco Marques" da área de Educação Física.

Reduzir os danos ao meio ambiente; reciclar é dar outro fim para o lixo; Reutilizar materiais descartáveis". Professora de Artes da Escola "Mariana das Graças".

A política dos 3R's quando é cumprida, ajuda a tornar a sustentabilidade eficaz e mais atuante, sendo assim, diminuindo a geração de mais resíduos descartáveis, contribuindo no meio social, ambiental mas também no meio cultural e econômico. Machado (2012, p.1) tem uma visão simplificada, mas bem ampla sobre a política pública de resíduos sólidos: 
Adotar uma política pública preventiva ambiental equivale a uma antecipação de comportamentos danosos ao meio ambiente e à saúde pública. No caso dos resíduos sólidos, a prevenção vai concretizar-se pela implementação de um dos seis tipos de planos: o Plano Nacional de Resíduos Sólidos; os planos estaduais de resíduos sólidos; os planos microrregionais de resíduos; os planos intermunicipais de resíduos sólidos; os planos municipais de gestão integrada de resíduos sólidos e os planos de gerenciamento de resíduos sólidos. 0 fim primacial da prevenção é evitar o dano, na sua forma mais ampla. Somente quando não for possível a evitação total do prejuízo ambiental, é que será aceito um comportamento redutor ou mitigador do dano.

Podemos ver também bons princípios dos conceitos, nas respostas de alguns educadores entrevistados, com certo nível aceitação e entendimento plausível e aceitável dos 3R's da sustentabilidade (reciclar, reutilizar e reduzir):

Reduzir para evitar desperdícios, reciclar para contribuir com o meio ambiente e reutilizar para diminuir a poluição ambiental. Professora de Língua Portuguesa da Escola "Francisco Marques".

Reduzir o consumo (consumir somente o necessário); reciclar materiais (transformar algo para não virar lixo); reutilizar (dar nova utilidade de algo para não ser mais um lixo. Professora de Geografia da Escola "Walmeire Borges".

Na questão 19 “o que você entende por sustentabilidade?”, seguindo a mesma linha de pensamento da questão anterior, busca compreender de uma forma geral, como os professores entendem o tema sustentabilidade. 0 que tivemos foi um leque variado de respostas das mais simples até as mais complexas:

É um conjunto de ações individuais e/ou coletivas que visam melhorar as condições de vida em uma determinada população que ocupa e depende dos recursos naturais para sobreviver. Professor de História da Escola "Francisco Marques".

Entendo por apoiar, conservar ou cuidar, com relação a natureza, ela se destaca como devemos agir, se aplicando ela em três vertentes, o social, ambiental e econômico, os três precisam andar juntos para que de fato a sustentabilidade aconteça. Professora de Educação Física da Escola "Francisco Marques".

Até algumas respostas mais simples e menores, mas que não deixam de estarem corretas e fazendo sentido:

Preservação e desenvolvimento econômico sendo gerenciados de forma adequada. Professor de História da Escola "Mariana das Graças".

São ações voltadas para desenvolver o mercado sem agredir o meio ambiente. Professora de Matemática da Escola "Francisco Marques".

Podemos encontrar muitas respostas padrão como "respeitar o meio ambiente", "viver de forma sustentável", "respeitar o meio ambiente", não que essas afirmações estejam erradas. Também temos respostas em branco, uma minoria, pois 75\% responderam a essa pergunta. Segundo a ONU (2010), “todos sabem que é impossível colocar uma cerca em volta da floresta e esperar que, por conta disso, não haja desmatamento. Se a decisão de proteger a floresta não for acompanhada de perspectivas de desenvolvimento econômico, de inclusão social e de geração de empregos não há como se garantir a proteção ambiental", exemplificou Luiz Alberto Figueiredo Machado, que é subsecretário-geral de Meio Ambiente, Energia, Ciência e Tecnologia do Ministério das Relações Exteriores (MRE).

Rev. Bras. Gest. Amb. Sustent., 2020, vol. 7, n. 16, p. 537-552. 
Chegando à última pergunta do questionário, questão número 20 "Sua escola realiza ações sustentáveis? Cite quais?". 80\% responderam e $20 \%$ deixaram em branco. Dentre os que responderam, 31,25\% disse que não há uma ação sustentável, 68,75\% disse que sim, mas todos citaram a mesma prática sustentável, o cultivo de uma horta, o que é verdade pois na visita as escolas foi visualizado as hortas.

Quanto à motivação para a inicialização dessas ações sustentáveis, foi citado durante uma das visitas, a iniciativa de um professor ou de um funcionário da escola em construir uma horta, motivo esse citado por Trajber e Mendonça (2006, p. 87) que realizaram uma pesquisa em algumas escolas dos Estados de Amapá e Pará:

Quanto à motivação inicial para o desenvolvimento de ações de Educação Ambiental, verifica-se nos dois estados a indicação de três motivos principais: em primeiro lugar, a iniciativa de um professor ou de um grupo de professores; em segundo lugar, a existência de um problema ambiental na comunidade; e em terceiro lugar, a adoção de diretrizes das secretarias estaduais e ou municipais.

\section{Conclusão}

Com o intuito de compreender o entendimento dos professores do município de Capitão Poço sobre a percepção da educação ambiental e sustentabilidade observamos que os educadores possuem noções básicas sobre os temas. Temas como ecologia foram abordados, mas os educadores que participaram da referida pesquisa possuem experiências com algumas técnicas na área de ensino/aprendizagem com a temática. Alguns entrevistados demonstram e tomam para si o papel de mediador de conhecimento, didaticamente falando, proporcionando assim uma tomada de posição crítica e reflexiva, tendo como principal argumento o diálogo.

Alguns entrevistados demonstram que precisam adotar novos métodos em sua aula, pois será importante para se conquistar uma melhor discussão e entendimento sobre o conceito de sustentabilidade e outros assuntos. Apenas com pequenas atitudes o processo não muda. É preciso sensibilizar e pôr em prática novas metodologias de ensino, e mudar a forma como é trabalhado na escola a temática da Educação Ambiental. Precisamos provocar e cobrar as instituições municipais sobre a temática com ações práticas e socioambientais para a sociedade com políticas públicas.

\section{Conflito de interesses}

Os autores declaram que não houve conflito de interesses.

\section{Referências}

Bortolon, B.; Mendes, M. S. S. A importância da educação ambiental para o alcance da sustentabilidade. Revista Eletrônica de Iniciação Científica, v. 5, n. 1, p. 118-136, 2014. Disponível em: <https://www.univali.br/graduacao/direito-itajai/publicacoes/revista-deiniciacao-cientifica-ricc/edicoes/Lists/Artigos/Attachments/984/Arquivo 6.pdf >. Acesso em: 28 out. 2019.

Brambilla, L.; Matsushita, M.S. Técnicas de compostagem no ambiente escolar. In: Hamerschmidt, I.; Oliveira, S. Alimentação saudável e sustentabilidade ambiental nas escolas do Paraná. Curitiba: EMATER, 2014. p.173-197. Disponível em: <http://www.educadores.diaadia.pr.gov.br/arquivos/File/educacao_ambiental/alimentac ao_saudavel_sustentabilidade_ambiental.pdf>. Acesso em: 30 maio 2020. 
Candiotto, L.Z.P. Considerações sobre o conceito de turismo sustentável. Revista Formação, v. 1, n. 16, p. 48-59, 2009.

Castoldi, R; Bernardi, R; Polinarski, C.A. Percepção dos problemas ambientais por alunos do ensino médio. Revista Brasileira de Ciência, Tecnologia e Sociedade, v. 1, p. 56-80, 2009.

Cruz, P.; Monteiro, L. (Orgs.). Anuário brasileiro da Educação Básica 2019. São Paulo: Moderna, Todos pela Educação, 2019. Disponível em: <https://www.todospelaeducacao.org.br/_uploads/_posts/302.pdf>. Acesso em: 25 nov. 2019.

Courela, C.; César, M. Promovendo a sustentabilidade: Uma experiência de partilha entre a escola e a comunidade envolvente. Revista Electrónica de Enseñanza de las Ciencias, v. 5 , p. 75-98, 2006.

Cuba, M. A. Educação ambiental nas escolas. Revista ECCON, v. 1, n. 2, p. 23-31, 2010.

Effting, T. R. Educação ambiental nas escolas públicas: realidade e desafios. Curitiba: Universidade Estadual do Oeste do Paraná, 2007. (Monografia).

Espíndola, J. A. A.; Guerra, J. G. M.; Almeida, D. L. Adubação verde: estratégia para uma agricultura sustentável. Seropédica: Embrapa Agrobiologia, 1997. (Documentos, 42).

Gil, A.C. Como classificar as pesquisas? 2002. Disponível em: <http://www.madani.adv.br/aula/Frederico/GIL.pdf>. Acesso em: 05 nov. 2019.

Jacobi, P. Educação ambiental, cidadania e sustentabilidade. Cadernos de Pesquisa, n. 118, p. 189-205, 2003. https://doi.org/10.1590/S0100-15742003000100008

Kato, D. S.; Carvalho, N. V.; Kawasaki, C. S. A contextualização na educação ambiental: análise de um curso de formação de professores da educação básica intitulada "meio ambiente e você professor - uma rede de saberes". Anais do VI Encontro "Pesquisa em Educação Ambiental", Ribeirão Preto, p. 1-16, 2011. Disponível em: <http://www.epea.tmp.br/viepea/epea2011_anais/busca/pdf/epea2011-0128-1.pdf>.

Acesso em: 10 maio 2020.

Layrargues, P. P. 0 cinismo da reciclagem: o significado ideológico da reciclagem da lata de alumínio e suas implicações para a educação ambiental. In: Loureiro, C. F. B.; Layrargues, P. P.; Castro, R. S. (Orgs.). Educação ambiental: repensando o espaço da cidadania. São Paulo: Cortez, 2002. p. 179-219.

Machado, P. A. L. Princípios da política nacional de resíduos sólidos. Revista do Tribunal Regional Federal da 1⿳亠丷厂 Região, v. 24, p. 25-33, 2012.

Martins, E. R. S. B. Sustentabilidade e as escolas da rede municipal do Município de Salinópolis, Estado do Pará. Belém: Universidade Federal do Pará, 2018. (Monografia).

MEC - Ministério da Educação. Parâmetros curriculares nacionais. Brasília: MEC, 1997.

Medeiros, M. C. S.; Ribeiro, M. C. M.; Ferreira, C. M. A. Meio ambiente e educação ambiental nas escolas públicas. Âmbito Jurídico, 2011. Disponível em: $<$ https://ambitojuridico.com.br/cadernos/direito-ambiental/meio-ambiente-e-educacaoambiental-nas-escolas-publicas/>. Acesso em: 01 maio 2020.

Morgado, F. S. A horta escolar na educação ambiental e alimentar: experiência do Projeto Horta Viva nas escolas municipais de Florianópolis. Santa Catarina: Universidade Federal de Santa Catarina, 2006. (Monografia). 
Narcizo, K. R. S. Uma análise sobre a importância de trabalhar educação ambiental nas escolas. Revista Eletrônica do Mestrado em Educação Ambiental, v. 22, p. 86-94, 2009.

Reigota, M. 0 estado da arte da pesquisa em educação ambiental no Brasil. Pesquisa em Educação Ambiental, v. 2, n. 1, p. 33-66, 2007. https://doi.org/10.18675/2177580X.vol2.n1.p33-66

Silva, R. C. A falsa dicotomia qualitativo-quantitativo: paradigmas que informam nossas práticas de pesquisa. In: Romanelli, G.; Biasoli-Alves, Z. M. M. Diálogos metodológicos sobre prática de pesquisa. Ribeirão Preto: Legis-Summa, 1998. p. 159-174.

Silva, R. L. F.; Campina, N. N. Concepções de educação ambiental na mídia e em práticas escolares: contribuições de uma tipologia. Pesquisas em Educação Ambiental, v. 6, p. 2946, 2011.

Souza, M. T. S.; Ribeiro, H. C. M. Sustentabilidade ambiental: uma meta-análise da produção brasileira em periódicos de administração. Revista de Administração Contemporânea, v. 17, n. 3, p. 368-396, 2013. https://doi.org/10.1590/S1415-65552013000300007

Sulaiman, S. N. Educação ambiental, sustentabilidade e ciência: o papel da mídia na difusão de conhecimentos científicos. Ciência \& Educação, v. 17, n. 3, p. 645-662, 2011. https://doi.org/10.1590/S1516-73132011000300008

Trajber, R.; Mendonça, P. R. 0 que fazem as escolas que dizem que fazem educação ambiental? Brasília: MEC/UNESCO. 2006.

Informação da Licença: Este é um artigo Open Access distribuído sob os termos da Licença Creative Commons Attribution, que permite uso irrestrito, distribuição e reprodução em qualquer meio, desde que a obra original seja devidamente citada. 